is worth in Shanghai about one dollar per kilogramme. tum, and is softer than Japan wax, but is not exported, trum lbotu. Japan wax is obtained from the kernels
of the fruit of Rhus succedanea, vernicifera, and syl vestris. Its preparation is one of the principal indus
tries of Kinsin, the best kind coming from the province

SIBLEY COLLEGE LECTURES.-1892-93.

BI THE CORNELL UNIVERSITY NON-RESIDENT LECThe Genesis and Exodus of Steam.

By GEORGE H. BabCoCK, of New York.

IN the beginning, before time was born, when cre ative energy first began to be exerted, there emanated
from Deity himself-because there was nothing else
from which to create it-a primal form of matter the first created thing. What it was we have not been !
told, but if we suppose that the Creator has followed from the first the plan of evolving the coinplex fron the simple, it is probable that it was that thing teristics. From this point of view it is not improbable that the first thing made was hydrogen, the least ponin its atomic construction, for which reason it has been
chosen by scientists as the unit of the chemical scale, chosen by scientists as the unit of the chemical scale,
and looked upon by many as the basal element from
which all others have been made. But, whether it be which all others have been masal element, it is a fact
the prinal creation or the basal hydrogen conserves in a greater degree than anythat hydrogen conserves in a greater degree than any-
thing else known to us that eneryy which, itself a
divine essence, is manifest to us under different forms which we call light, heat, electricity and force. Among the earliest created things must also have
been oxygen, for it forms a very large part of most
substances found in nature. This element is remark able in many ways, but mostly in that it possesses an affinity for every other known element. Is it there-
fore too much to say that it symbolizes another great
attribute of its Creator-infinite, universal love? It was these two elements which the All-wise chose
to unite, to form that which was to become the greatto unite, to form that which was to become the great-
to create in his own image and place upon the earth in the then future ages. And so oxygen and hydrogen were married, and in
their union brought forth steam in its highest state of energy, ready for its mission in the world, and when,
in fulfiling that mission, it had imparted very mueh
of its energy to the things around it, it condensed and of its energy to the things around it, it condensed and
became water, and when this had further given of its heat to things colder than itself, it became ice, and so in its triune forms of steam, water and ice, this min-
eral has gone on from that day to this performing
some of the most important and stupendous works in the preparing of this earth for the abode of man. As steam it has shaken and riven the earth, opened and
erupted volcanoes, dissolved many other ninerals, and
deposited them in form or place where they can be made of use, besides having a large share in pushing forward the early vegetation which went to form our
coal fields. As water it has fertilized the earth, de-
nuded the surface in many places, and deposited its
spoils on others as beds of clay and other alluvial matspoils on others as beds of clay and other alluvial mat-
ters ; served as a medium for stratifying and even
forming many of our rocks, and supported hordes of aquatic animals, whose remains are to-day a promi-
nent part of the earth on which we live. As ice it has nent part of the earth on which we live. As ice it has
had no less part in shaping the face of the earth, dig-
ging down mountains, plowing out valleys and transging down mountains, plowing out valleys and transhomes, building up hills and plains innumerable with rocks to form the soil in which vegetation thrives.
And, since the advent of man upon the earth, this earliest of the compounds has proved itself to be his
most obedient and useful servant, as well as his constant friend.
Perhaps you are startled to hear steam classed as a mineral, but if we accept the evidence of science that
hydrogen is a metal, then steam and water are a me-
tallic oxide, and as truly mineral as are oxide of iron in iron ore, or oxide of alumina in the ruby and $\mathrm{em}$ erald.
We imitate this original genesis of steam in a small way in the oxy-hydrogen flame, and in fact in all our gen. The same process is also taking place on a pro-
digious scale in nature, particularly in the sun, for the telescope and the spectroscope have revealed to us
enormous flames of hydrogen, frequently shooting thousands of miles beyond the photosphere of the sun,
which cannot be aught else than the festive dance at the nuptials of these two parents of steam.

If to produce one pound of steam or water we mingle
$\frac{1}{9}$ of a pound of hydrogen with $\frac{8}{9}$ of a pound of oxygen, and ignite them by a spark of electricity or otherwise, and enough heat is liberated to have melted 20 pounds
of steel or 70 pounds of gold, or 350 pounds of lead if it could all have been imparted thereto $;$ and enough, if tons one foot high, or to have exerted two and one-half horse power for an hour. The temperature produced,
if we suppose the steam to retain its specific heat and
the whole quantity to be burned at once, would be the whole quantity to be burned at once, would be
$12,000^{\circ} \mathrm{F}$., or about that wished for by the exasperated
Nebuchadnezzar when he ordered the furnace for the Nebuchadnezzar when he ordered the furnace for the
reception of his recalcitrant subjects to be heated seven
times hotter than it was wont to be heated. It is believed, however, to be impossible ever to attain that excessive temperature by combustion, because long be-
fore it is reached, the action of dissociation takes place,
and the gases refuse to burn further until some of the heat has been radiated or otherwise disposed of. Nev-
ertheless the oxy-hydrogen flame is $s$ till the hottest thing known to us except the electric spark, and is stances. When it is caused to heat lime or magnesia
to incandescence it gives us the well-known calcium to incandescence it gives us the well-known calcium
light, the most powerful artificial light known-except
that of the electis But to return to our pound of steam. We found it
at its birth endowed with an almost inconceivable energy, more than that developed by the combination of
the same quantity of any other elements. This energy
or heat it readily imparts to surrounding objects, and
it is therefore employed by man to melt, solder, subli-
mate, heat, or otherwise perform work for him. When
it has given off enough heat to have raised 37 pounds
of water from the freezing to the boiling point, it will
itself become water, and if we still go on reducing its
temperature by absorbing its heat, until it has given
off enough more to heat 320 other pounds of water one
degree, or have melted $21 / 4$ pound of ice, it will have
become solid ice itself ; but even then it will have re-
tained a quantity of heat, so much so that an amount
equal to $3 / 4$ of that given off since it first became water
would have to be extracted before it could arrive at the
condition of absolute cold.
But we are more interested as a matter of practice in
the regenerating of steam for our use for even if we the regenerating of steam for our use, for even if we
found it in sufficient abundance in nature, as in gey
sers and hot springs, it would scarcely be capable of sers and hot springs, it would scarcely be capable of
being harnessed for our service like that which is made
in boilers. Water is the most abundant thing in nature. Hence we have no lack of material, and all that is necessary is to restore to it so much of the heat energy it it can best work in the harness which we have prepare for it. And for this purpose we find another bountiful pro-
vision of kind nature, in the vast accumulations of stored energy, which we call fuel. How much of this
energy thus stored for our use is that which was given energy thus stored for our use is that which was given not know, but that many of our coal fields were laic bath in those ages of hot humidity which preceded the
ad vent of life upon the globe, is doubtless true. How-
ever, we mine these stores of coal and put a part of their energy into a portion of water, and so transform Let us watch the

Let us watch the process. We have say one pound of water, the same quantity that we have just seen
made by original synthesis, and we put it in the bot-
tom of a vessel in which we have fitted a perfectly tight and frictionless piston. To the bottom of this
vessel we apply our heat, assuming that the vessel itvelf has neither specific heat nor power of radiation,
whereby we are enabled to apply our heat to the water without interference or losses. We start with the water at the temperature of melting ice, $32^{\circ} \mathrm{Fah}$., and
occupying a certain cubic space, which for our purpose
we may consider as a unit. As heat is added its temwe may consider as a unit. As heat is added its temmal unit, but for a time this produces no expansion. does not follow the almost universal law of expansion by heat, until it arrives at about $8^{\circ}$ above the freezing
point, so that when our great bodies of water, in cool-
ing off during the winter months, have arrived at that point, the cold water no longer sinks, but remains on
top to freeze and form a crust of ice, which preserves op to freeze and form a crust of ice, which preserves
rom extinction the animal life within the depths be-
neath. At about $40^{\circ}$ the water is at its greatest densi$y$, and from that time on it will be found to expand rrived at $212^{\circ}$, by the addition of $1801 / 2$ thermal units,
when, if our piston be supposed to be without weight, and to be held down only by the pressure of the atmosphere at the level of the sea, it will have come to
what is known as the "boiling point." This boiling haracteristic is that, when at this point, the water is neapable of becoming any hotter, and every addition a portion into steam; in other words, the water has all
the heat it can hold-as water-at that pressure. Our
French friends have therefore named this the "point French friends have therefore named this the "point
of saturation," and water in this condition they call
"saturated." It is a good term, and deserves to be Our pound of water, now at $212^{\circ}$, has increased siight-
Out in bulk, so that it occupies about 4 per cent. more
pace than before, and it has therefore forced up the space than before, and it has therefore forced up the
piston to that extent, and performed an amount of
work equal to the distance into the pressure, or, say, work equal to the distance into the pressure, or, say,
the equivalent of one pound raised seventeen inehes,
and heat energy to that value has disappeared. The and heat energy to that value has disappeared. The
heat we have put into our pound of water up to this
point has been employed in three ways-first doing point has been employed in three ways-first, doing
coming the internal resistance of the water to the separation of the molecules causing expansion ; and third, mall as to be scarcely appreciable, being less than mall as to be scarcely appreciable, being less than
one one-hundred-thousandth. The second is consider-
able, and has been estimated to be about 60 per cent.
of the whole, while the third is the remaining portion, of the whole, while the third is the remaining portion,
say 40 per cent., or 72 thermal units.
Now, however, at the point of saturation, an entirely Now, however, at the point of saturation, an entirely
so longas any water remains, does not raise the temper ature any higher, but every unit of heat so added converts a small portion of the water-a little over one
one-thousandth part-into steam, having a bulk 1,622 times greater than the water from which it is made,
but the same temperature. Here one unit of heat has
raised the piston 7,800 times more than the same quanraised the piston 7,800 times more than the same quan-
tity of heat had done before, and of course accom-
plished that much more mechanical work, or about the equivalent of 60 pounds raised one foot high. But, as
a unit of heat, when all converted into mechanical a unit of heat, when all converted into mechanical
work, is equal to 778 pounds raised one foot high,
only about 8 per cent. of our heat unit has been used up in overcoming external resistance, and the balovercoming their attraction for each other while way add 966 heat units to our pound of water,
each one accomplishing the result just described,
when it will be found that every particle of the pound of water has become steam at atmospheric pressure. But the whole of these 966 units have pro-
duced no effect whatever upon the thermometer whence this heat has been termed "latent," which in the business of raising steam. It is not lost, how- weight or in winding up a spring is lost. It is simply
stored ready for use. That portion which was spent in raising the piston against atmospheric pressure i
given back when the piston is allowed to fall, and that used in the internal work of expansion is given back either as heat or work when the molecules again come
nearer each other to form water, just the same as the nearer each other to form water, just the same as the
watch spring gives back the force you exerted in winding it up.
The action we have thus described is that which takes place every time you boil water in a tea kettle orother place every time you boil water in a tea kettle or other
open vessel, the atmospheric air taking the place of
the piston; but the action in a steam boiler is somewat different.

If we had placed our pound of water in a close vessel of infinite resistance to rupture, and just large enough out making steam. If we suppose the envelope to and the water to retain the same specific heat as at been added the same quantity of heat as was required
before to make it all into steam, instead of indicating
212 deg. in the thermometer as before, it will now show nearly 1,200 deg., or be red hot, at which high temperasquare inch, and if permitted to expand against atmoBut what we call a steam boiler, though it does not
deg. as before boil stean, but rather generates steam by boiling
water, is a close vessel of sufficient strength to stand the pressure we desire to carry, and somewhat larger than the water we put into it. Let us suppose we into it one pound of water, as before, at 32 deg. As a we
idd heat up to the point of saturation, we perceive no differencefrom the former conditions, but at that poin another set of conditions come into play. As we go on
adding heat, part of the water is vaporized, as before, but, being prevented by the envelope from expanding, the surface of the water is increased, raising the point
of saturation gradually, so that not all the heat added
now is employed to vaporize the water, a part going to increase the temperature of the fluid up to the new point of saturation. But as the steam is not allowed
to expand as much, a less amount of heat is expended
in that work, and none at all is required for external work, so that the proportion of the water evaporated or each unit of heat added remains nearly the same,
decreasing very slightly. When, therefore, we have added the 1146 heat units which before, under one atosphere of pressure, were sufficient to heat the fluid
will evaporate the whole of the pound, the pressure
wisen in our vessel to nearly thirty atmo. pheres, and a small amount, say 10 per cent., of the water will still be present as water at the temperature
of saturation normal to that pressure, or 450 deg. If now we go on adding heat until we have added 80
units more, we will find all the water evaporated and
have a cubic foot of steam at a pressure of 475 pounds have a cubic foot of steam at a pressure of 475 pounds
per square inch above a vacuum.
If however, instead of carrying the pressure to this high point we had added only sufficient heat to raise the pressure to 100 pound per square inch absolute
we should then have evaporated a little over $1 / 4$ of our
pound of water, and the remainder would have been pound of water, and the remainder would have been And if now we begin to draw off the steam for use, $n$ which steam is generated for all the purposes required for the uses of mankind. No matter what the size of the boiler, or what is its construction, or the
pressure carried, the principles which underlie the pressure carried, the principles which underlie the
generation of steam within it are the same, and are il-
lustrated in the small boiler we have supposed. Many differences may exist as to theirad vantageous applicazation of the value of the heat applied, but these ques-
tions do not belong to the present discussion. Having now considered at length the making of steam,
let us look into the question of what becomes of it. It is not one of the things made to keep. It will not, like
gold or the pyramids of Egypt, remain unchanged for
ages. Its life is as evanescent as a cloud. It is made to-day; to-morrow, nay, perhaps another moment,
and it is not. Whither does it go, and what is the nature of its taking off? There are three ways in which steam may cease to
exist. 1st. It may convert its heat irito work, and die exist. 1st. It may convert its heat irito work, and die
in performing the task set it by its master. 2d. It may
give up its heat to another body, having done which it give up its heat to another bod y, haver. 3d. It may be-
come dissolved in the air, and merge itself into that benefactor as well as tormenter of our race, "general benefactor as well as tormenter of our race, "general
humidity." It is, however, in the first two modes of
quitting existence that it makes itself especially useful This transformation of heat into dynamic as well as into other forms of energy, and vice versa each into
any other, is one of those strange things in nature any other, is one of those strange things in nature blow of the flint upon a piece of steel, or the friction
of one piece of wood upon another, would produce
heat and fire was known from the earliest days, but heat and fire was known from the earliest days, but
that the heat produced was the direct result and a comparatively recent date. And still more recently
did we come to understand that for every force exerted either by man or by animals, or in any of the processes of nature, an equivalent quantity of heat, or some
other form of energy, disappears. The changing of heat into light is well illustrated by the incandescence of a piece of white-hot iron or a burning coal into elec-
tricity by the thermic pile. Work, or force in action,

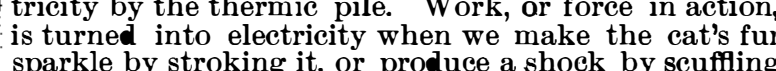
along the carpet, as well as by the steam engine driv ing a dynamo. motor, to heat in the incandescent filament of our glow lamps and in the electric welding process, into
light directly in the Aurora Borealis and the Geissler tubes. Our electric lighting, however, is done through
the intermediary instrumentality of heat. We first set heat loose from its prison in coal, and after trans-
ferring it to steam, transform a part of it by a steam 
\begin{tabular}{l|l|l|l|l} 
engine into dynamic energy, then change this into & 000,000 tons would be within the truth. This will add & the \\
electricity, that into heat, and the heat into light. & another $30,000,000$ tons to the coal account, making a & st
\end{tabular}

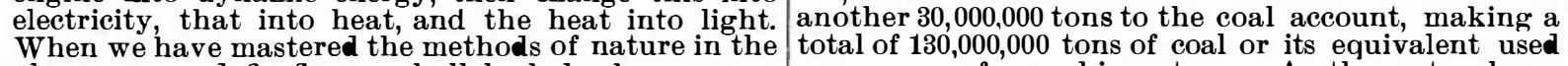
glowworm and firefly, we shall look back upon our present methods of lighting as crude indeed.
This is wandering from our subject, but it may lead us better to und erstand why steam gives up its energy and life when it is set to performing work.

tion contains all the heat it can hold at that of saturaOn the contrary, saturated steam contains the least instant any of its heat, no matter how little, is subtracted, or turned into another form of energy, a corWhen we had our pound of water heated red hot, and at a pressure of $20,000 \mathrm{lb}$. per square inch, if we had
loaded it by a piston to that pressure, gradually reduss unt it as it expanded and the pressure gre we should have found that it had exerted about half to become steam at atmospheric pressure under those 690 heat units more than were necessary when it expanded all into steam without doing work, that done; or, in other words, if we had allowed it to exheat, about half of it would have remained water at 212 deg. at 475 pound total pressure, had we allowed it to exbeen about 220,000 foot pounds of work done, and about one-quarter of the steam would have been conIn the same manner, when the steam in the cylinder
of an engine performs work by pushing the piston before it against a resistance, that work, necessitating transformation of heat, robs the steam, so that at once a portion is condensed. In this way every hourly
horse power of work done in an engine by saturated steam demands the condensation of about two and one-half pounds of that steam to supply the energy very expensive, but alas! our machinery and method are so very imperfect, and the conditions of the pro-
blem are such, that from five to twenty-five times that amount of steam, in addition, is compelled to pass amount of work; the balance, being discharged into

use to us. engine may be divided into three portions, one of
which is condensed in doing work, another and generto the walls of the cylinder, to make up for heat wasted, both through these walls and from the evapThe third portion, much larger than either of the others, serves as a more or less necessary backing or
companionship for the others. Thus when we had our pound of steam at 20,000 pounds pressure per
squareinch, we found that only half of it would be condensed in doing the work of expanding against reutilized in a perfect steam engine without any pre-
ventable losses. When our pound of steam was at 475 pounds pressure, we found only 25 per cent. condensed ruple expansion engines of this day the proportion is a little less than one-fifth; in the best non-condensing is sometimes only one-fortieth of the steam which is actually used in doing the work. So it comes to pass the City of Paris, the Umbria, or the Teutonic, crosses up its life to furnish the energy which pushes the ship with its cargo through the water, while other seventeen or eighteen thousand tons, in inseparable comocean, and takes again the form of water.
We have in the United States about 4,000,000 horse power of steam engaged in manufacturing, very little of which runs less than 10 hours per day, and much of
it 24 hours, so that we may assume 13 hours as a fair average. There are, also, 35,000 locomotives of per36,000 miles per year, which would require, say, six hours per day, which, with steamboats, etc., make an each day, so that not less than 150,000 tons of steam is doing work, while at least eleven times as much mor is compelled to keep it company and pass out of ex-
istence, mostly without further use. This calls for some $100,000,000$ tons of coal, or the equivalent of other fuel-but this is not all that goes to make steam.
There is much steam used for heating, which

enters an engine. Two reasons may be given why first, it will carry more heat for a given weight, and second, when it has given up its heatitinstantly drops
out of the way to make room for another portion to deliver its heat at the same spot. In this it is in
marked contrast to air or gases, which, at atmospheric marked contrast to air or gases, which, at atmospheric pressure and the same temperature as steam of ten tact with the surface which absorbed its heat, and pre-
venting the access of hotter portions thereto. Hence steam is very extensively used as a means of carrying heat from the place where it is convenient to generate it to the place where it is wanted for use, as in house
heating, boiling, drying, etc. The amount used for
this purpose is not easy to estimate. The New York Steam Company is the largest provider of steam for house heating, and it supplies during the colder or for the year, summer and winter, say 1,600,000 tons. It is roughly estimated that the amount used in the
city of New York alone is 18,000,000 tons per year, and that there is used in the whole United States, say, and boiling in various processes not counted in manu-
facturing, and we may safely say that a total of 200,

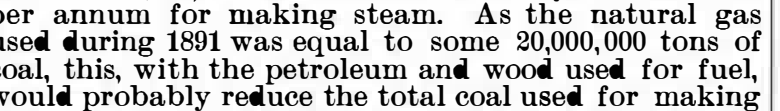
1891 , was $150,000,000$ gross tons.
We now come to the third way in which steam makes Air at a temperature of 58 deg., which is near the vapor which is not satisfied until it has drank in about one per cent. of its weight. The higher its tempera-
ture the greater its appetite, and the lower it goes in The thermometric scale, the less moisture it will hold. cent. of its own weight, while at 38 deg., $1 / 2$ of one per cent. fils it to repletion. So when the teakettle is
boiling over the hob, the rising steam is readily ab-
sorbed or dissolved by the air, and becomes invisible
And when the passing locomotive throws a cloud of And when the passing locomotive throws a cloud of
steam into the atmosphere, it, too, soon disappears, as completely as if it never had existed, and, though the not exist under such a pressure, but becomes water this vapor is uncondensed. It is only when the air becomes over-saturated, as by cooling it until the amount
contains is too great for its appetite, that thi vapor takes on the visible form and becomescloud or
fog, and is precipitated in the form of rain. Nature in herown processes provides for a sufficient absorption needed, but the steam artificially generated and thrown
now nd to our modes of thinking is prodigious. One concern alone, the Carnegie Steel Company, with its difthan fifteen hundred tons of steam. We have already the United States approximg through the engines in nnum. Some of this is condensed in doing work, and some in condensing engines, but we are safe to con-
clude that, together with the steam from dye houses, evaporating kettles for sugar and salt making, and in
culinary operations, not less than that amount of six hundred million tons is annually thrown into the air, affect the amount of rainfall? It probably does, but the processes of Nature are on so grand a seale that even his inconceivable amount may sink into insignificance
Let us see : The annual rainfall east of the Rocky to over 60 inches in others, with an average of not les than 36 inches. This amounts, in that territory, $t$ in the whole country were confined to this side of the Rocky Mountains, it could add not over $\frac{1}{150}$ of one per enough to furnish one evening dew. Thus grander are the operations of Nature's workhouse than the most that, however much we may in future ages increase has made for her own purposes. supersede steam, and that then it may be expected that steam will make its final exodus from the service or nearly all purposes for which it is used is made by is employed under present conditions, the greater will be the demand for steam. But it is not outside the way to convert the heat of combustion into electricy direct, without the intervention of a steam engine and when that time comes, if come it does, we may
well conceive that one of the uses of steam will be done way with. But there is little probability that ther will ever be found a more efficient means than steam cargo capacity excels all other available substances, ery of making the wheels go round, this oldest servant a a common carrier of that necessity of man's existence and prime element in his manufacturing processes o that the genesis and exodus of steam will probably gan.

\section{THE DRAUGHTOMETER.}

As an outcome of the stringent legislation as to overAding ships, consequent upon the Plimsoll agitation the Board of Trade now require a degree of accuracy
in loading which is scarcely possible in many cases,
save by a method often much to the detriment of owners, $i$. e., keeping on the "safe side," and probably osing twenty-five or fifty tons of freight. Cases have een frequent of late of shipmasters being fined, in imprisonment for allow merged from 1 in. to 4 in. beyond their load mark. In most of these cases the alleged overloading takes place under circumstances over which the master can scarceof finding the draught by 6 in. figures on stem and by barges, lighters, quay walls, etc., is troublesome, water reaches the top or bottom of the figures referre to, the water line at any of the intermediate inches can of surface water, such as is generally experienced in pen roadsteads, and even in rivers under certain conare of course, not nearly accurate enough for the requirements of the Board of Trade. The provision, therefore, of a simple and inexpensive means by which marks, and the owner get the full benefit of the ship' marks, and the owner get the full benefit of the ship' An apparatus designed to enable masters to loa would probably reduce the total coal used for making
steam to about one-half the amount mined, which, in to a perceptible amount, the ample provisions Nature
and of Glasgow, and is now being made and supplied by makers, of Broomielaw, Glasgow. The apparatus in
question, which the inventor names "The Draughto-
meter," is the outcome of a series of years' study of the ubject, and of actual experience with an experimental apparatus on board ships which have been under Capeived the approval of such eminent authorities a Trade; Mr. T. J. Dodd, of Lloyd's Register, etc.: and many ship masters and owners and their representavantages to be derived from its use. The principle of the dra.nghtometer is very simple-is almost analo-

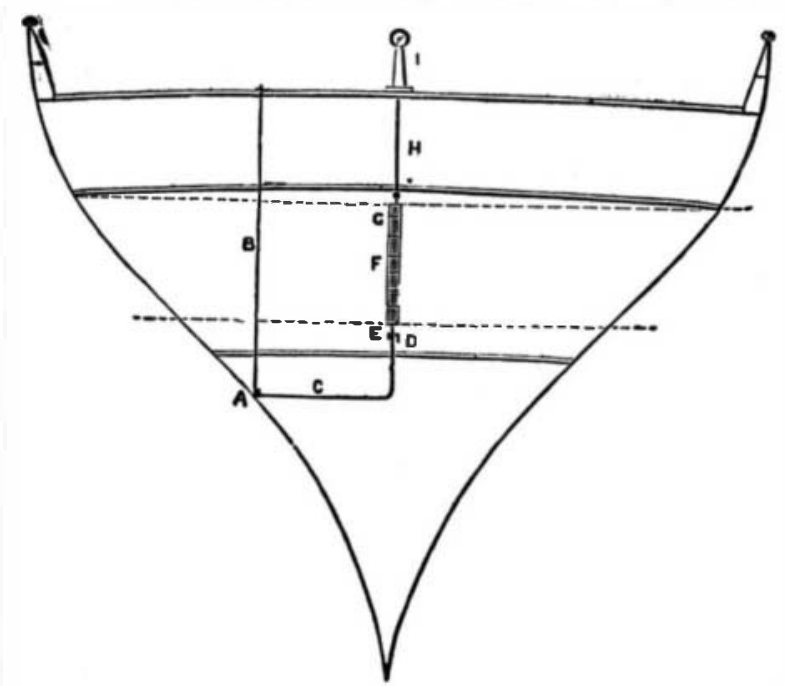

THE DRAUGHTOMETER.

purposes to which it may be made subservient on
board ship, are skillfully thought out and arranged. it consists, as will be seen from our illustrations, essena convenient situation forwa d, and in simllar dial fixed fit, on which are marked the feet and inches correthe ship's displacement due to such draughts, both in the ship's displacement due to such draughts, both in
salt and in fresh water. Traversing the middle of this
vertical graduated dial is a glass tube, which is practivertical graduated dial is a glass tube, which is practically a continuation of a vertical pipe, and its horizontal complement leading down the center line of the
vessel and thence across to the ship's skin, where there is a sea cock, $A$, for the free admission of the water the level of the minimum load line, and consequently is free to operate throughout the whole range at varyports, and of all intermediate variations between the minimum and maximum draughts during the course

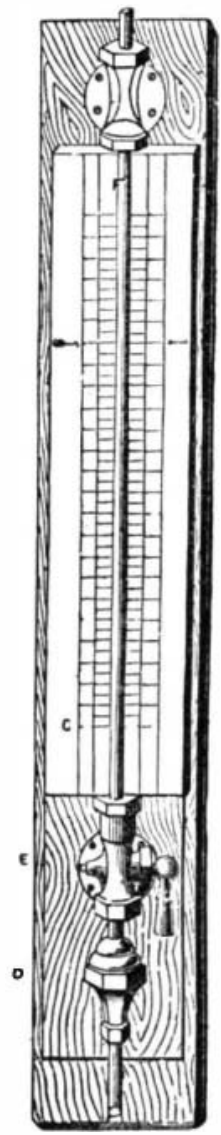

DRAUGHTOMETER.

In the interior of the glass tube-which of range in height from $2 \mathrm{ft}$. to $6 \mathrm{ft}$. just as the range ship may determine-is a float formed of aluminum, be, representing the loading or discharging. The surdraught. The arrow marks on the dial at $K$ represent the maximum load water mark, which, in fixing the cisely correspond with, or be in the same horizontal cisely correspond with, or be in the same horizontal
plane with, the official load mark on the outside of the plane with, the official load mark on the outside of the and in fresh water, corresponding to the draughts-a 